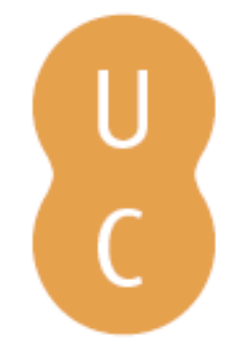

\title{
nommalina
}

\section{Computational thermochemistry: accurate estimation and prediction of molecular thermochemical parameters}

\author{
Autor(es): $\quad$ Morais, Victor M. F. \\ Publicado por: Imprensa da Universidade de Coimbra \\ URL \\ persistente: URI:http://hdl.handle.net/10316.2/31325 \\ DOI: $\quad$ DOI:http://dx.doi.org/10.14195/978-989-26-0240-0_9 \\ Accessed : $\quad$ 26-Apr-2023 12:31:28
}

A navegação consulta e descarregamento dos títulos inseridos nas Bibliotecas Digitais UC Digitalis, UC Pombalina e UC Impactum, pressupõem a aceitação plena e sem reservas dos Termos e Condições de Uso destas Bibliotecas Digitais, disponíveis em https://digitalis.uc.pt/pt-pt/termos.

Conforme exposto nos referidos Termos e Condições de Uso, o descarregamento de títulos de acesso restrito requer uma licença válida de autorização devendo o utilizador aceder ao(s) documento(s) a partir de um endereço de IP da instituição detentora da supramencionada licença.

Ao utilizador é apenas permitido o descarregamento para uso pessoal, pelo que o emprego do(s) título(s) descarregado(s) para outro fim, designadamente comercial, carece de autorização do respetivo autor ou editor da obra.

Na medida em que todas as obras da UC Digitalis se encontram protegidas pelo Código do Direito de Autor e Direitos Conexos e demais legislação aplicável, toda a cópia, parcial ou total, deste documento, nos casos em que é legalmente admitida, deverá conter ou fazer-se acompanhar por este aviso.

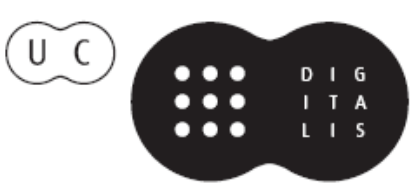


J. S. Redinha

J. da Providência

A. J. C. Varandas

Editors

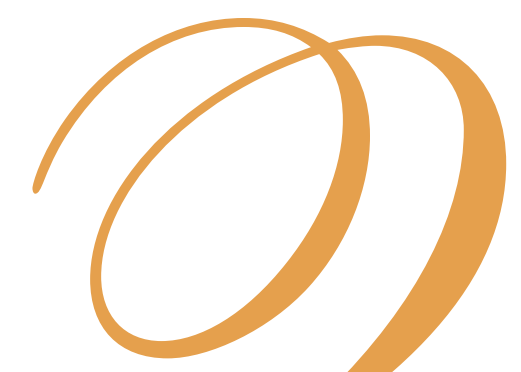

in Chemistry and Physics

A tribute to the memory of

Professor Couceiro da Costa

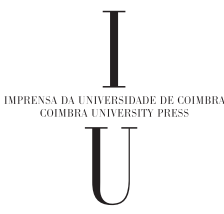




\title{
9. Computational Thermochemistry: ACCuRAte ESTIMATION AND PREDiction OF MOLECULAR THERMOCHEMICAL PARAMETERS
}

\author{
Victor M. F. Morais* \\ Instituto de Ciências Biomédicas Abel Salazar, ICBAS, Universidade do Porto, \\ P-4099-003 Porto, Portugal
}

\begin{abstract}
The problems involved in the Quantum Mechanical calculation of molecular energies are identified, with special emphasis on the problem of correctly describing the effects of the correlated electronic motions. Some of the available Quantum Mechanically based methods for the calculation of molecular energies are then briefly described and their application to some selected systems are detailed. The quality of the results so obtained illustrates the usefulness and the accuracy achieved through the use of conveniently based computational techniques and the fact that contemporary thermochemists have now the real possibility of complementing their experimental measurements with well founded very accurate calculated data or, even, of obtaining original and very accurate thermochemical data entirely from computational techniques.
\end{abstract}

\subsection{Computational Methods}

Since the introduction of Quantum Mechanics, in the first quarter of twentieth century, very important advances in chemistry have emerged, particularly in those fields where accurate numerical data is required, such as thermochemistry and chemical kinetics. Indeed, it is now recognized that Quantum Mechanics constitutes the ultimate, most accurate and complete description of the behaviour of matter at the atomic and molecular scale and, as such, much hope has been put in the development of efficient computational methods which can provide accurate estimates of the molecular thermochemical parameters.

\footnotetext{
"Email address: vmmorais@icbas.up.pt
} 
Such achievements would contribute to definitely establish computational thermochemistry as a reliable complement to experimental thermochemistry, thus opening new frontiers to the study of chemical species whose instability or short lifetime has prevented experimental analysis up to now.

This talk is concerned with the difficulties found when the methods of Quantum Mechanics are to be applied to real systems and with the description of some state-of-the-art computational techniques which have been developed to provide accurate molecular thermochemical parameters. We will describe also some applications of those computational methods with particular emphasis to the analysis of the stability of selected molecular species.

The task of accurately describing the properties of molecular systems starting from the concepts of Quantum Mechanics would appear as very straightforward if it is accepted that such theory provides the most accurate and complete description of the behaviour of matter at the atomic and molecular level. According to this point of view it becomes obvious that in order to obtain reliable and accurate estimates of molecular thermochemical parameters it suffices to solve the corresponding Schrödinger equation

$$
\hat{H} \Psi=E \Psi
$$

which is a differential eigenvalue equation providing, as solutions, the energy, $E$, and the wavefunction, $\Psi$, of the stationary states of the molecular system. In this equation $\hat{H}$ is the Hamiltonian operator, acting on the wavefunction $\Psi$, which depends explicitly on the spatial and spin coordinates of the electrons and the nuclei. Even though Schrödinger equation can be easily solved for hydrogen atom and, in general, for any system with just one electron, in which case it provides accurately the experimentally observed energies, when we proceed to more complex systems, with at least two electrons, such exact solution reveals unattainable, and some kind of approximate solution must be seek instead. The vast majority of the methods used to obtain approximate solutions to the Schrödinger equation is based on a general approximation introduced to the model of the wavefunction used to describe the system under study. This 
approximation assumes that each electron in the system moves independently of the other electrons (an independent particle model is thus adopted) and the interactions among the various electrons are accounted for through the introduction of a potential energy function representing just the time average of the instantaneous interactions between each electron and the remaining ones. Thus, each electron will then be described by a particular spatial function, $\varphi_{i}$, which depends on its spatial coordinates. According to the Pauli antisymmetry principle each such spatial function, generically called molecular orbital, can really accommodate two electrons, as long as they have different spin coordinates, $\alpha$ or $\beta$. The wavefunction describing the overall electronic system can then be represented by a function with the following general form:

$$
\Psi=\frac{1}{\sqrt{n !}} \operatorname{det}\left|\left(\varphi_{1} \alpha\right)\left(\varphi_{1} \beta\right)\left(\varphi_{2} \alpha\right) \cdots\right|
$$

where the determinant, called Slater determinant, ensures the proper antisymmetry of the wavefunction, as is required for systems constituted by fermions. The energy of the system can then be obtained through variation of the molecular orbitals in order to minimize the expectation value of the Hamiltonian operator:

$$
E=\langle\Psi|\hat{H}| \Psi\rangle
$$

Such variational procedure leads to a system of coupled differential equations, called Fock equations, whose solutions are the molecular orbitals, $\varphi_{i}$. Thus, in the Hartree-Fock model each electron feels a potential which is the average of the instantaneous potential created by the other electrons. Such replacement of the true (instantaneous) potential by the average potential ensures that the Hartree-Fock method can easily lead to approximate solutions of the Schrödinger equation. However, those solutions will certainly reflect the nature of the adopted approximations, in the sense that they should incorporate the errors associated with the assumptions assumed for the wavefunction model. We must stress that the solutions of the Fock equations (the molecular orbitals, $\left.\varphi_{i}\right)$ are obtained in numerical form, as tables of numerical values, instead of some kind of analytical form, which would be preferable for those aiming to 
analyse the properties of the electronic systems in terms of the contributions resulting from the subsystems constituting them, e.g., the properties of a molecule as resulting from contributions of their individual atoms. This situation soon conducted to a proposal involving the mathematical representation of the molecular orbitals as expansions in terms of selected mathematical functions, collectively called basis set:

$$
\varphi_{i}=\sum_{k=1}^{N} c_{i, k} \chi_{k}
$$

The adoption of such representation had the very important consequence of allowing the replacement of the system of coupled differential equation, the Fock equations, by a system of algebraic equations, the so-called Hartree-FockRoothaan equations, involving the coefficients of the individual members of the basis set in each molecular orbital, $\varphi_{i}$. In this way, the required flexibility of the wavefunction which allows for the minimization of the expectation value (9.3) is thus transferred to the variation of the molecular orbital coefficients, whose values must then be optimized in order to (variationaly) minimize the expectation value of the energy. The basis sets are usually chosen to consist of atomic centered functions which are often assimilated to the corresponding atomic orbitals. Since the basis sets used in practice are necessarily limited in size, their capability of description of the molecular orbitals is also limited and, as such, the resulting expectation value for the energy is affected by numerical errors. We can thus observe that, up to this point, two possible sources of errors are present in the computational procedure we are describing: on the one hand the errors resulting from the particular model (9.2) of wavefunction adopted by the Hartree-Fock scheme and on the other hand the limitations resulting from using finite sets of basis functions for the molecular orbital representation. Even if we used a complete set of basis functions to represent the molecular orbitals (so eliminating the second source of inaccuracy) the energy obtained by the Hartree-Fock method, which is then called Hartree-Fock energy, $E_{\mathrm{HF}}$, would be in error when compared with the observed (non-relativistic) one, $E_{\text {exact }}$. Such 
Table 9.1. Correlation errors for two simple molecular systems.

\begin{tabular}{lccccc}
\hline & $E_{\text {exact }}$ & $E_{\mathrm{HF}}$ & \multicolumn{1}{c}{$E_{\text {corr }}$} & $\%$ & $E_{\text {corr }} / \mathrm{kcal} \mathrm{mol}^{-1}$ \\
\hline $\mathrm{H}_{2}$ & -1.1749 & -1.1340 & -0.0409 & 3.48 & $\sim-26$ \\
$\mathrm{H}_{2} \mathrm{O}$ & -76.435 & -76.065 & -0.37 & 0.48 & $\sim-232$ \\
\hline
\end{tabular}

error:

$$
E_{\mathrm{corr}}=E_{\text {exact }}-E_{\mathrm{HF}}
$$

which is always negative, since the Hartree-Fock method is variational, is called correlation energy, or correlation error, a designation reflecting its phenomenological origin related to the fact that the motions of the electrons with different spins are described as completely non-correlated by Hartree-Fock theory. Even though this error seems often very small when we consider its value relative to the total electronic energy (typically less than $1 \%$ of the total electronic energy), its contribution to the properties which are of interest to chemists, like bond energies or, more generally, reaction energies, is so large that its very existence precludes using the energies so obtained to get reliable estimates of such energetic parameters. Table 9.1 shows typical contributions of the correlation energy for small molecular systems. We can observe from that Table that the absolute errors resulting from neglecting the correlation energy are unacceptable, even for the most simple systems, when we come to consider accurate description of reaction energies. Indeed, the absolute errors shown in that Table are by far much larger than the errors chemists can accept, i.e., about $1 \mathrm{kcal} / \mathrm{mol}$.

We must, in addition, stress that real calculations for truly interesting molecules can only be conducted with severe limitations on the basis sets completeness, and, as such, the actual errors involved in the results are even much more important than the correlation error, because we don't even reach the HartreeFock limit in such cases. So, if quantum mechanical techniques, based on the Hartree-Fock wavefunction, are to be fruitfully used to get reliable energetic information, we must proceed by simultaneously correcting the Hartree-Fock method along two independent routes: $(i)$ by improving the model (9.2) of the wavefunction and (ii) by using basis sets as close to completeness as possible. 
A logical route to get better results than simple Hartree-Fock theory can provide follows directly from the observation that the Hartree-Fock solution (9.2) usually involves more molecular orbitals, $\varphi_{i}$, than those which are needed to accomodate the electrons constituting the molecule. Thus, even though only the lowest energy molecular orbitals, $\varphi_{i}$, are used to construct the Slater determinant (9.2), a considerably higher number of molecular orbitals is obtained in the procedure of variationally minimization of the energy. The remaining molecular orbitals are thus unoccupied in the configuration (9.2); such unoccupied orbitals are called virtual orbitals. Distribution of the electrons by the low energy molecular orbitals, as in (9.2), can thus be viewed as just one of the many possible ways of distributing the electrons by the available molecular orbitals. It has been found that the description provided by the Hartree-Fock method can be improved by adding to the single-determinant wavefunction (9.2) a number of configurations resulting from alternative distributions of the electrons by the remaining available virtual molecular orbitals. This procedure leads to an alternative description of the molecular wavefunction which can then be symbolically represented as:

$$
\Psi=a_{0} \Psi_{0}+\sum_{i, a} a_{i}^{a} \Psi_{i}^{a}+\sum_{i, a} \sum_{j, b} a_{i j}^{a b} \Psi_{i j}^{a b}+\cdots
$$

In this equation $\Psi_{0}$ represents the Hartree-Fock wavefunction (9.2), while $\Psi_{i}^{a}$ a Slater determinant (also called configuration) obtained by promoting one electron from occupied molecular orbital $i$ to virtual molecular orbital $a, \Psi_{i j}^{a b}$ the doubly excited configuration obtained by simultaneously promoting two electrons from occupied orbitals $i$ and $j$ to virtual orbitals $a$ and $b, \ldots$ etc. This linear combination of Slater determinants is the philosophy of the so called Configuration Interaction (CI) method. Simply put, a CI wavefunction is a linear combination of Slater determinants (configurations) whose coefficients are to be determined variationally. Of course, in real calculations this linear combination must be severely truncated in order to lead to workable tasks. The simplest standard CI method which improves upon Hartree-Fock is a CI calculation which adds all singly and doubly substituted determinants (CISD). However, the CISD 
wavefunction has soon fallen out of favor because truncated CI wavefunctions short of full configuration interaction are not size-extensive, meaning that their quality degrades as the size of the molecules becomes larger. This is a general result about the Configuration Interaction method: when used in a truncated way the CI series leads to results which are not size consistent. A formulation of Configuration Interaction which remains size consistent even when arbitrarily truncated, called quadratic CI (QCI), has been proposed, the simplest method to improve Hartree-Fock results being, in this case, designated by QCISD and being now preferred to the earlier implementations.

An alternative attractive formulation involves perturbation theory using the Hartree-Fock wavefunction as the zeroth-order wavefunction and the difference between the complete Hamiltonian and the Hartree-Fock Hamiltonian, i.e., the correlation energy, as the perturbation. This is the Møller-Plesset formulation of perturbation theory and is based on a perturbational series for the energy, involving successively higher order corrections to the this parameter:

$$
E=E_{0}+E_{1}+E_{2}+E_{3}+\cdots
$$

together with a corresponding series for the wavefunction. As in the case of the CI method, the complete perturbation treatment leads to the best description we can get with the used basis set. Indeed, both expansions, variational and perturbational, are conceptually very similar, to the point that when considered non-truncated they will lead exactly to the same result: the exact one. Naturally, in real calculations, only approximate treatments can be conducted, taking account of a limited number of terms in the perturbation series: the simplest way of improving the Hartree-Fock energy (which is correct to the first order, thus being just the sum of the first two terms in the perturbational series) through perturbation methods involves including just the second order contributions, leading to the so called MP2 method. Successive perturbative methods thus adopt the designations MP3, if all terms up to third order are included in the perturbational series, MP4, when all terms up to fourth order are included, and so on. One important advantage of perturbation techniques over the CI method 
is that truncated (to any order) perturbation calculations always lead to size consistent results, while truncated configuration interaction calculations do not. The two methods are, otherwise, thought as equivalent in the sense that including all possible configurations in a combination which is compatible with the spin symmetry of the molecular state we are aiming to describe, leads to the so called full CI (FCI) limit, and describes the system so rigorously as including all terms in the perturbational expansion. Thus, both methods will provide naturally the best possible description we can obtain with the basis set which is being used.

There are also some other important methods, of which we will only refer the coupled cluster (CC) methods because of their growing importance as a size-consistent alternative to configuration interaction. As with the CI method, coupled cluster techniques are also usually implemented in very truncated versions, leading to different CC flavours: thus CCSD considers only single and double excitations, while $\operatorname{CCSD}(\mathrm{T})$ also includes a perturbative account of the effect of triple excitations, etc. We have just mentioned some procedures which are most often adopted in order to surpass the natural limitations of the HartreeFock formulation, i.e., some useful post-Hartree-Fock techniques.

Conversely, by proceeding along the other route to better describe the system, i.e., by enhancing the capability of representation of the basis set in order to get so close as possible to basis set completeness, we will obtain the better description possible, restricted to a chosen model of the wavefunction. So, it seems obvious that any systematic search for accurate calculation of molecular energetic parameters procedures must simultaneously progress along both directions, performing a kind of two-dimensional progression, in order to include the larger possible number of terms in the configurational or perturbational expansions, thus approaching the FCI limit and, additionally, to extend, as possible, the basis set in order to approach the complete basis set (CBS) limit. Such technique would naturally lead to the exact solutions, that is, to the energies observed experimentally, when we reach simultaneously both individual limits, FCI and CBS, as is schematically depicted in Figure 9.1. Of course this limit can only be attained if we are just considering very simple electronic systems, more complex 


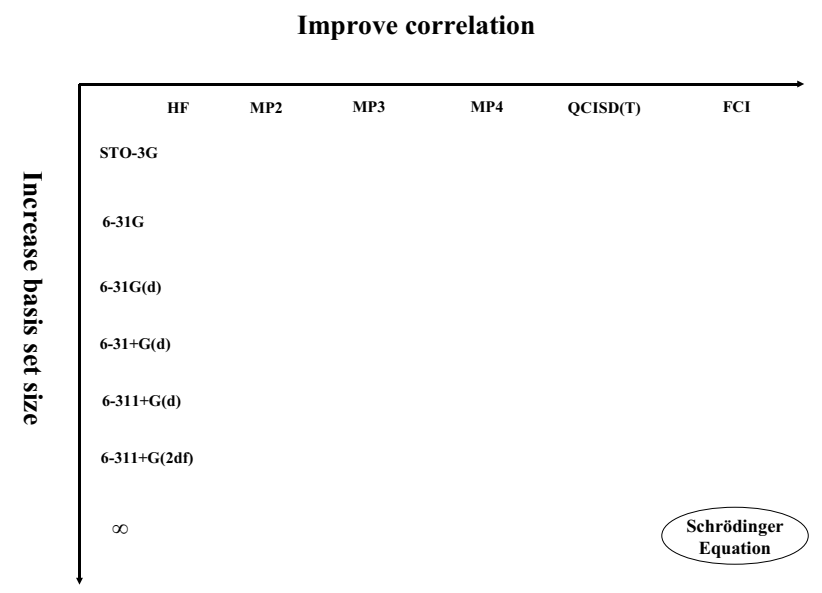

Figure 9.1. Bidimensional route to exact solution of Schrödinger equation.

systems leading to so computationally demanding tasks that the calculations are really precluded by the necessarily limited resources. In order to further proceed and provide reliable insights into the properties of more complex real systems we thus need to accept the incorporation of additional approximations to the above protocol. A large number of computational recipes have already been suggested and tested; we will limit ourselves to a very short description of some of those methods, particularly those we have selected to conduct calculations on some interesting molecules. Almost all accurate procedures for obtaining energetic data share the basic philosophy, which involves using less sophisticated, yet reliable, calculations to obtain the molecular geometry and the vibrational frequencies (both of these are generally very time consuming tasks, but are essential for forthcoming calculations) and then introduce the correlation energy estimates from a much more sophisticated level of theory and with the most extense basis set compatible with available computational resources.

Such composite procedures would ideally be rigorously formulated and should conduct to the equivalent result of a single calculation much more sophisticated than each of the individual calculations involved. The most accurate of the methods we currently use, G3, belongs to the series of techniques named 


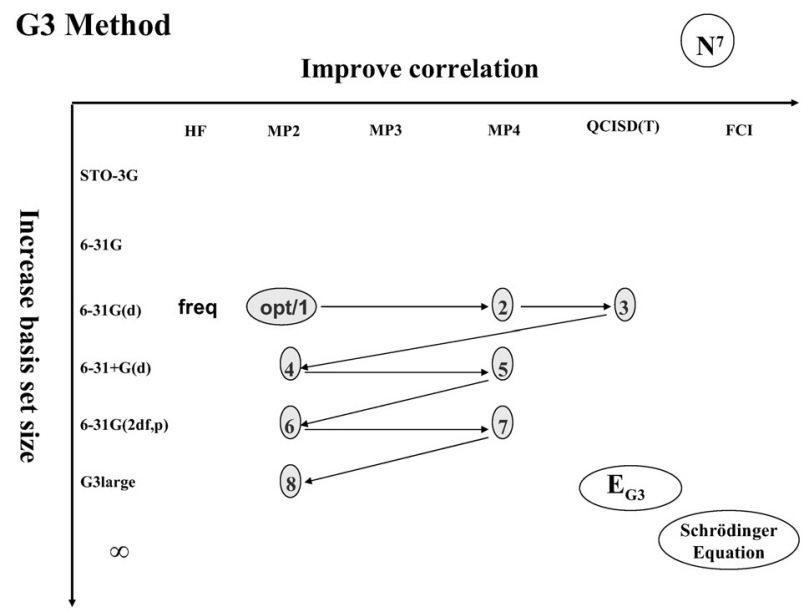

Figure 9.2. Schematics of the individual calculations involved in the G3 method.

G(aussian)- $N(N=1,2,3)$, originally suggested by Pople and co-workers [1]. The detailed sequence of individual computations integrating a G3 calculation are schematically depicted in Figure 9.2. The final energy at the G3 level is obtained as a MP4 energy calculated with the 6-31G(d) basis set properly corrected for several effects:

$$
E_{\mathrm{G} 3}=2+(3-2)+(5-2)+(7-2)+(8-1)-(4-1)-(6-1)
$$

The correction terms represent several effects described as follows:

$(5-2) \equiv \Delta E(+)$ is a correction aiming to account for the effect of using diffuse (+) functions;

$(7-2) \equiv \Delta E(2 d f, p)$ is a correction for the use of higher polarization functions on nonhydrogen atoms and $\mathrm{p}$ functions on hydrogen atoms;

$(3-2) \equiv \Delta E(\mathrm{QCI})$ corrects for correlation effects beyond fourth order of perturbation theory using the method of quadratic configuration interaction;

$(8-1)-(4-1)-(6-1) \equiv \Delta E(\mathrm{G} 3$ Large $)$ is a correction for larger basis set and nonadditivity effects. Thus, as we can observe from the scheme, the G3 energy is really a presumably good approximation to a QCISD(T) energy calculated with a large basis set (G3 Large), but obtained without really conducting such very expensive calculations. 
This computational method has been much tested now and reveals a very accurate computational method. Its computational cost scales formally as $N^{7}$, where $N$ is roughly the number of atoms in the molecule, and so becomes very heavy even for moderately sized molecules. As such, other methods have been selected to proceed with the calculation of thermochemistry properties. Some less expensive variants of G3 have been suggested: G3B3 is a G3 method which involves using the B3LYP method to obtain the geometry and frequencies while G3(MP2) replaces the MP4 steps of the original procedure by calculations at the MP2 level. Among many other available methods we also adopted some of those based on a slightly different philosophy. The basis of the multi-coefficient correlation methods (MCCM) of Truhlar and coworkers $[2,3]$ is similar to that adopted in the Gaussian- $N$ series but, instead of simply adding the individual corrections to the reference calculations, these are introduced after being scaled, or weighted, by optimizable parameters. These parameters are then optimized so that the errors in the atomization energies (or perhaps other energetic parameter or even a combination of several parameters) of a set of representative test molecular systems are minimized. The use of adjustable parameters allows for the inclusion of lower levels of correlation and/or smaller basis sets to achieve a given level of accuracy. Thus the cost of both methods we usually use to predict thermochemical parameters, MCUT and MCQCISD, scale "simply" as $N^{6}$, thus allowing to consider much larger molecules than the G3 method. The individual calculations involved within these methods are graphically depicted in Figures 9.3 and 9.4, respectively for MC-UT and for MC-QCISD. MC-UT method aims to reproduce MP4(SDQ) calculations with the modified Gaussian 3 semidiffuse (MG3S) basis set, by judiciously combining several individual calculations as:

$$
E_{\mathrm{MC}-\mathrm{UT}}=1+c_{1}(2-1)+c_{2}(3-2)+c_{3}[(4-2)-(3-1)]+c_{4}(5-3)
$$

while MC-QCISD aims to reproduce QCISD calculations obtained with the modified Gaussian 3 semidiffuse (MG3S) basis set, by combining several individual 


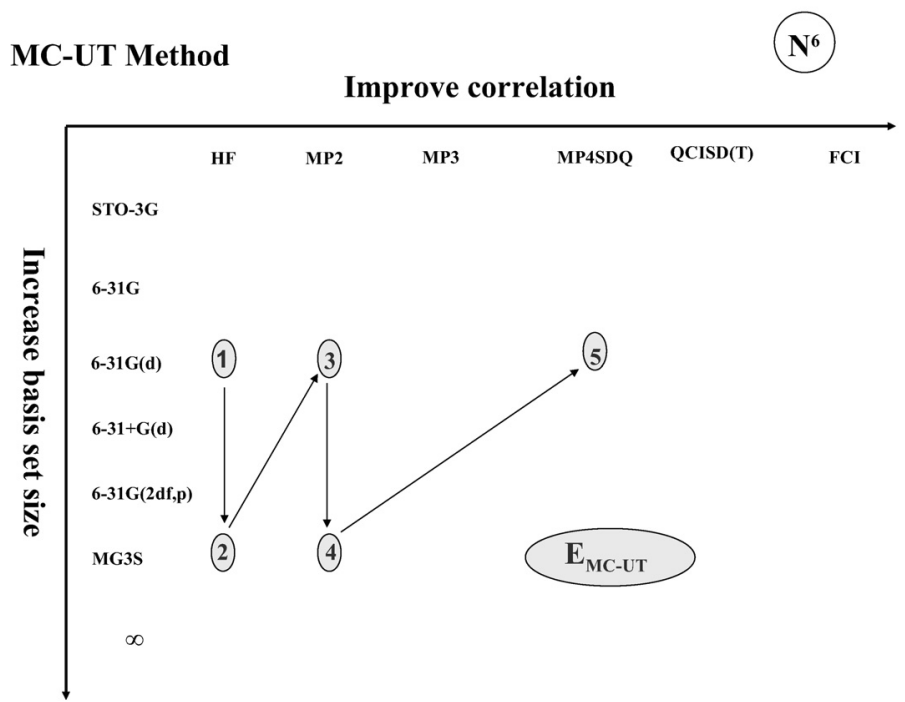

Figure 9.3. Schematics of the individual calculations involved in the MCCM/MCUT method.

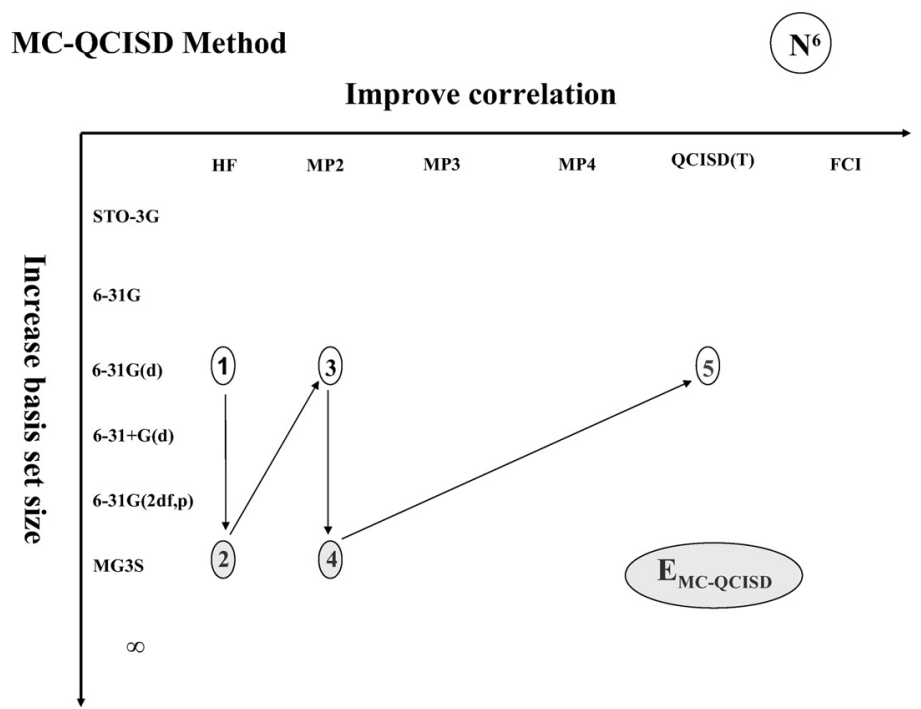

Figure 9.4. Schematics of the individual calculations involved in the MCCM/MCQCISD method. 


\section{CBS Extrapolation}

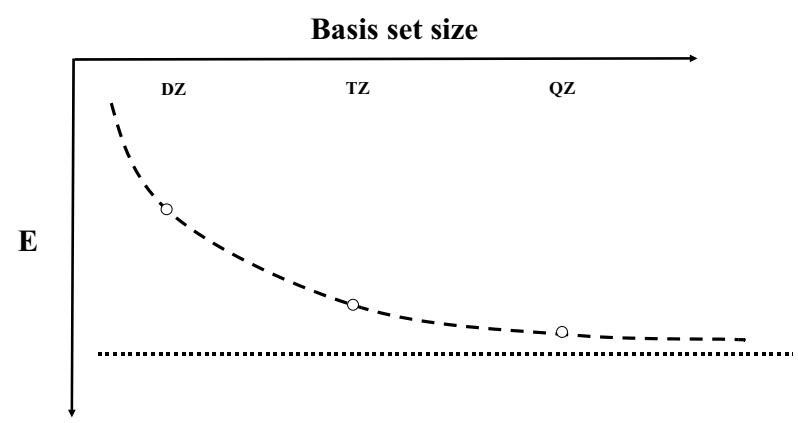

Figure 9.5. Schematic representation of CBS extrapolation technique.

calculations as:

$$
E_{\mathrm{MC}-\mathrm{QCISD}}=1+c_{1}(2-1)+c_{2}(3-2)+c_{3}[(4-2)-(3-1)]+c_{4}(5-3)
$$

In addition to the aforementioned methods other relevant techniques based on somewhat different principles have also been suggested. The CBS (complete basis set) series of methods [4] share the following individual calculations:

(i) (U)HF/6-31G ${ }^{\dagger}$ geometry optimization and frequencies;

(ii) MP2(FC)/6-31G optimized geometry for subsequent calculations;

(iii) (U)MP2/6-311+G(3d2f,2df2p) energy and CBS extrapolation;

(iv) $\mathrm{MP} 4(\mathrm{SDQ}) / 6-311 \mathrm{G}(d(f), p)$ energy;

(v) (QCISD(T)/6-31+G energy.

The innovative key step is the use of an extrapolation of the results of the MP2/6$311+\mathrm{G}(3 d 2 f, 2 d f, 2 p)$ calculation to the complete basis set (CBS) limit (Figure 9.5). This extrapolation is based on the asymptotic behaviour of the natural orbitals and allow the obtention of very accurate results without having to conduct the most expensive individual steps involving very high levels of electron correlation and very extensive basis sets.

Much important in the context of basis set extrapolation techniques has been the introduction [5] of classes of hierarquical basis sets specially designed to suc- 
Table 9.2. Fraction of correlation energy of water molecule accounted for by several computational methods.

\begin{tabular}{lccccccccc}
\hline & HF & MP2FC & MP2FU & MP4 & CCSD & CCSD(T) & $\begin{array}{c}\text { CCSD(T) } \\
\text { (Full) }\end{array}$ & G3 & Exact \\
\hline Energy & -76.058 & -76.319 & -76.332 & -76.333 & -76.325 & -76.332 & -76.346 & -76.382 & -76.435 \\
$\%$ & 99.51 & 99.85 & 99.87 & 99.87 & 99.86 & 99.87 & 99.88 & 99.93 & 100 \\
$\Delta\left(\mathrm{kcal} \mathrm{mol}^{-1}\right)$ & -236 & 73 & -65 & -64 & -69 & -65 & -55 & -33 & 0.0 \\
\hline
\end{tabular}

cessively cover more extensively the available electronic space. These sophisticated basis sets use acronyms which indicate clearly their degree of completeness, e.g., cc-pVXZ, cc-pCVXZ, aug-cc-pVXZ, etc., where $X(\mathrm{D}, \mathrm{T}, \mathrm{Q}, 5,6, \ldots)$ indicates the cardinality of the basis set: $X=\mathrm{D}$ indicates a double- $\zeta$ quality basis set, $X=\mathrm{T}$ a triple- $\zeta$ quality, etc. This methodology aims thus to provide results which tend systematically and uniformly to those which will be obtained at the complete basis set limit. This way the extrapolation formulae become much more precise. Since the rate of convergence of the correlation part of the molecular energy is significantly slower than that of the Hartree-Fock component, it is usually adopted a separation of the molecular electronic energies into their components, each of which is then extrapolated independently. This route has been exploited in several works [6-8] and constitutes a much promising tool, which is believed to perform much better than the extrapolations based on classical Gaussian basis sets.

The real importance of the correlation energy and the difficulty of accounting for it in practice is well illustrated by the data in Table 9.2, which shows the fraction of the correlation energy of water molecule recovered by several computational methods (all data, except G3, obtained from calculations using the cc-pVTZ basis set on the MP2(FC)/6-31G* geometry).

We can observe that even the most sophisticated computational techniques still include errors which are exceedingly large when compared to chemically meaningful quantities. As a consequence, even if the size of the molecular species allows for the use of the most sophisticated techniques, it is nevertheless mandatory to combine the raw energetic results with judiciously chosen chemical reaction schemes in order to obtain a maximal cancellation of the errors still 
affecting both sides of reaction, a result which is more likely to be achieved the more "similar" are reactants and products in the chosen reactions. In this context the reaction schemes we use must preferably be, at least, of the isodesmic type, i.e., they must conserve the number and qualitative "types" of chemical bonds in passing from reactants to products, or even of the homodesmotic type (if, in addition, the number of atoms of each formal type in each hybridization state is also conserved), thus ensuring the desired error cancellation and a good description of the energetics by computational results. Very restrictive reaction types are however often not feasibly usable, mainly because no experimental accurate data is available for some of the involved species. In such cases we are compelled to use other types of reactions, particularly atomization reactions. Atomization reactions are very appellative since writing them involves no ambiguity, i.e., they are uniquely defined; however their use is likely to lead to a description which is prone to large inaccuracies. Indeed, since, by definition, all bonds in the molecule are destroyed in such reactions, these reactions are as far from an isodesmic reaction as possible and, as a consequence, no error cancellation occurs. Thus the task of calculating accurate atomization energies becomes very difficult when using atomization reactions.

Even though some of the methods we cited above are indeed very accurate computational techniques which allow the reliable prediction of the thermochemical parameters of chemical systems, their usefulness has serious drawbacks since their computational cost rises so steeply that they become unpractical unless we restrict the studies to very small molecular systems. In the context of the study of larger systems useful alternatives are provided by the methods based on density functional theory (DFT). Since the account these methods take of the electronic correlation effects is not exact, the usual implementations involve a considerable amount of empirical parameterization thus becoming conceptually very distant from the the philosophy of $a b$ initio theory. The main advantage of such methods is their much higher performance-to-cost ratio when compared to the wavefunction based methods, enabling their application to much larger molecular systems. A major drawback of DFT techniques, which has not been 
surpassed yet, is that, contrary to what happens with the methods based on the treatment of the wavefunction, there is no straightforward procedure allowing the systematic convergence of the results of DFT calculations obtained with truncated basis sets to the exact ones.

Additionally to the methods used to obtain the accurate values of the energy of the molecular systems, other additional tools are required to analyse the so obtained wavefunctions and several effects which can occur. Aromaticity, being a multifaceted and elusive molecular property observed in systems containing one or more cyclic arrangements of atoms, has been traditionally considered and analysed from three starting viewpoints: structural, energetic and magnetic. In our work we are mainly concerned with the analysis of the aromatic behaviour of molecules based on the consideration of their magnetic properties. In fact, these properties are likely to show special relationships to the microscopic phenomena which is believed to be the basis of aromatic behaviour, i.e., the circular delocalization of electrons. Briefly, the response of cyclic electronic systems to an external magnetic field is manifested through the creation of a ring current which, ultimately, will produce an induced magnetic field opposing the external magnetic field (aromatic behaviour) or reinforcing it (antiaromatic behaviour). In either case the net result will be observable in Nuclear Magnetic Resonance (NMR) experiments as the properties called nucleus chemical shifts. Since Quantum Mechanics can be used to calculate the molecular chemical shielding tensor, we can thus hope that this is a truly direct way of testing the emergence of the ring currents associated with the aromatic/antiaromatic behaviour, and will thus provide an objective test of the aromatic/antiaromatic behaviour itself. Using computational techniques based on Quantum Mechanics is indeed advantageous over NMR experiments since in this case we can even probe the ring current (chemical shielding) at any point within the molecule and not just at the nuclei. Thus, from the computational viewpoint, the relevant properties are the so called Nucleus Independent Chemical Shifts (NICS), as first suggested by Schleyer and co-workers [9].

Traditionally NICS are shown as the symmetric of the isotropic component of 
the chemical shielding tensor evaluated at the center of the rings or, in order to properly account for the nodal properties of the $\pi$-orbitals, and to minimize the (contaminating) effects of the $\sigma$ electronic framework, at some point above or below that geometric center; significantly negative values of the NICS are then associated with aromatic behaviour while positive values indicate antiaromaticity.

Additionally, NICS calculation are often combined with Natural Bond Orbitals (NBO) [10-13] analysis of the wavefunctions to get usefull insigths about the detailed contribution of selected orbitals to the magnetic properties. We can then separate unequivocally the effect of $\pi$-electrons on the calculated NICS, i.e., the individual effects on the observed aromaticity/antiaromaticity of the systems under analysis.

\subsection{Typical Results for Selected Molecules}

Unless otherwise stated, the equilibrium geometries of all studied systems have been determined from density functional theory using the Becke-3-parameter hybrid exchange [14] and the Lee_Yang_Parr [15] correlation density functional (B3LYP) together with two basis sets: 6-31G* [16] and 6-311G** $[17,18]$. The harmonic vibrational frequencies were obtained from the optimum B3LYP/631G* geometries using the same basis set and were scaled by a factor [19] of 0.9614 in order to correct for anharmonicity. More accurate energies were also obtained from single-point calculations at the most stable B3LYP/6-311G** geometries, using the triple- $\zeta$ correlation-consistent basis set, cc-pVTZ [5] together with the B3LYP functional. These optimized geometries were also used to obtain the energies at the MC-UT, MC-QCISD, while the calculations using the G3 type series of methods use their own optimized geometries. The NICS values were calculated using RHF/6-31G* wavefunctions derived from the B3LYP/6311G** geometries. The methodology used was developed by Schleyer and co-workers [9]. Two different NICS values were calculated for each ring and each molecule: one at the geometrical centre of the ring (i.e., the point whose coordinates are the nonweighted mean of the homologous coordinates of the 
heavy atoms of the rings), denoted $\operatorname{NICS}(0)$, and $1.0 \AA$ above the center of the ring, denoted NICS(1.0).

\subsubsection{Anthranil Aromaticity [20]}

Antranil (benzo[c]isoxazole, $\mathbf{I}$ ) is a highly unsaturated bicyclic nitrogenous heterocycle with $10 \pi$-electrons, distributed among two rings each one with $6 \pi$ electrons, and a single, classical resonance structure. Thus, each individual ring, as well as the anthranil molecule as a whole, satisfies the Huckel $4 n+2$ rule. We ask "is it aromatic?", for this species is $\pi$-isoelectronic/isoconjugate with its isomers 1,2-benzisoxazole (II) and benzoxazole (III), as well as with quinoline (IV) and isoquinoline (V), for which the presence of aromaticity seems unambiguous.<smiles>c1ccc2nocc2c1</smiles>

benzo[c]isoxazole [Anthranil]

(I)<smiles>c1ccc2oncc2c1</smiles>

benzo $[d]$ isoxazole

(II)<smiles>c1ccc2ocnc2c1</smiles>

benzo[d]oxazole

(III)

On the other hand, the carbon-carbon bond conjoining the two rings is an essentially single bond in that, like the corresponding bond in azulene (VI) and the Ph-Ph bond in biphenyl (VII), it is always a single bond in any resonance structure lacking a long bond (cf. the "Dewar" structure) or a dipolar/zwitterionic description.<smiles>c1ccc2ncccc2c1</smiles>

quinoline

(IV)

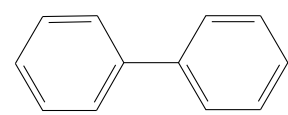

biphenyl

(VII)<smiles>c1ccc2cnccc2c1</smiles>

isoquinoline

(V)

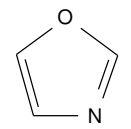

oxazole

(VIII)

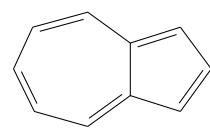

azulene

(VI)

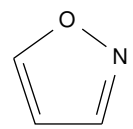

isoxazole

(IX) 
The energetics of anthranyl has been studied through the analysis of the following homodesmotic reactions:<smiles>c1ccc2nocc2c1</smiles>

Anthranil<smiles>c1cnoc1</smiles>

isoxazole<smiles>c1ccc2nocc2c1</smiles>

Anthranil<smiles></smiles>

benzo[ $[d]$ isoxazole<smiles>c1cocn1</smiles>

oxazole<smiles>c1cocn1</smiles>

oxazole<smiles>COc1cccc2ocnc12</smiles>

Benzoxazole<smiles>c1cocn1</smiles>

oxazole<smiles>c1ccc2ocnc2c1</smiles>

Benzoxazole

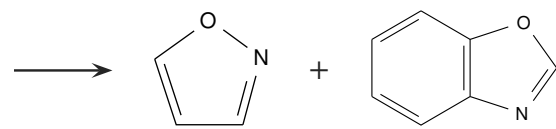

Benzoxazole

isoxazole

Anthranil benzo[ $[d]$ isoxazole<smiles>c1ccc2nocc2c1</smiles><smiles>CCC</smiles><smiles>N#Cc1ccccc1O</smiles>

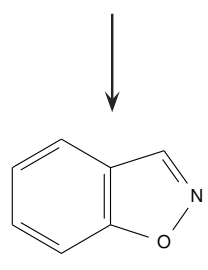

benzo[d]isoxazole

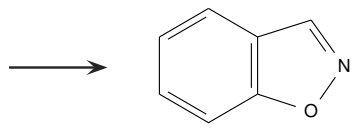


Table 9.3. Calculated and experimental reactions enthalpies at $298.15 \mathrm{~K}$.

\begin{tabular}{|c|c|c|c|c|c|c|}
\hline & \multicolumn{6}{|c|}{$\Delta_{r} H_{G}^{0}(T=298.15 \mathrm{~K}) / \mathrm{kJ} \mathrm{mol}^{-1}$} \\
\hline & \multicolumn{3}{|c|}{ B3LYP } & \multirow[t]{2}{*}{ G3(MP2) } & \multirow[t]{2}{*}{ G3 } & \multirow[t]{2}{*}{ Exp. } \\
\hline & $6-31 G$ & $6-311 G^{* * *}$ & cc-pVTZ & & & \\
\hline Reaction (R1) & -150.4 & -153.5 & -152.5 & -157.1 & -157.0 & $-(136.0 \pm 2.2)$ \\
\hline Reaction (R2) & -90.9 & -94.4 & -93.6 & -96.9 & -97.1 & $-(94.1 \pm 0.7)$ \\
\hline Reaction (R3) & -59.5 & -59.0 & -59.0 & -60.2 & -59.0 & $-(41.9 \pm 2.3)$ \\
\hline Reaction (R4) & -13.2 & -13.1 & -13.0 & -13.3 & -13.0 & - \\
\hline Reaction (R5) & -46.3 & -46.0 & -46.0 & -46.9 & -46.8 & - \\
\hline Reaction (R6) & -122.7 & -153.1 & -150.9 & -155.3 & -155.6 & $-(148.0 \pm 3.0)$ \\
\hline Reaction (R7) & -76.4 & -107.2 & -104.9 & -108.3 & -108.7 & $-(112 \pm 8.4)$ \\
\hline
\end{tabular}

ation of the auxiliary molecules were taken from Refs. 21,22). For the isomerization reactions $\mathrm{R} 1$ and $\mathrm{R} 2$, we obtain an experimental value for $\Delta_{r} H$ of $-(136.0 \pm 2.2) \mathrm{kJ} \mathrm{mol}^{-1}$, for the former, and $-(94.1 \pm 0.7) \mathrm{kJ} \mathrm{mol}^{-1}$, for the latter. These values are in good agreement with the results of our calculations and allow us to attribute the observed difference to a change in aromaticity of about $(41.9 \pm 2.3) \mathrm{kJ} \mathrm{mol}^{-1}$. By regarding reaction $\mathrm{R} 3$ as the sum of reactions R1 and R2, an experimental value for $\Delta_{r} H$ of $-(41.9 \pm 2.3) \mathrm{kJ} \mathrm{mol}^{-1}$ is obtained, which is the result of a balancing of isomerization energies and aromaticity change. So it seems that the hypothetical reaction $\mathrm{R} 4$ should essentially be thermoneutral, because isomerization energies plausibly cancel (1,2benzisoxazole $\rightarrow$ benzoxazole; oxazole $\rightarrow$ isoxazole) and also because there is no particular difference in aromaticity between the reagents and the products. Theoretical calculations give a value of about $-13 \mathrm{~kJ} \mathrm{~mol}^{-1}$ for this reaction, in good agreement with these assumptions. Note that the theoretical value of for reaction $\mathrm{R} 3$ is about $-59 \mathrm{~kJ} \mathrm{~mol}^{-1}$ (Table 9.3), which shows a deviation of $-17 \mathrm{~kJ} \mathrm{~mol}^{-1}$ from the experimental value. From the thermoneutrality of reaction R4 and by using the enthalpies of formation [21] of the gaseous species involved [oxazole: $-(15.5 \pm 0.5) \mathrm{kJ} \mathrm{mol}^{-1}$; isoxazole: $(78.6 \pm 0.5) \mathrm{kJ} \mathrm{mol}^{-1}$; benzoxazole: $(44.8 \pm 0.5) \mathrm{kJ} \mathrm{mol}^{-1}$ ] we estimate the enthalpy of formation of 1,2 benzisoxazole to be $(138.9 \pm 5) \mathrm{kJ} \mathrm{mol}^{-1}$. Similarly, for Equation R5 we estimate a value of $\Delta_{r} H$ of about $-(41.9 \pm 2.3) \mathrm{kJ} \mathrm{mol}^{-1}$ [the theoretical results for re- 
action $\mathrm{R} 5$ of $\mathrm{ca}$. $-46 \mathrm{~kJ} \mathrm{~mol}^{-1}$ corroborate this estimation] and consequently we obtain a value of $(138.9 \pm 3.1) \mathrm{kJ} \mathrm{mol}^{-1}$ for the enthalpy of formation of 1,2-benzisoxazole. This value can favourably be compared with the estimates obtained from atomization energies at he G3(MP2) and G3 levels (Table 9.4)

To further corroborate this estimate, we considered the ring-opening isomerization reaction $\mathrm{R} 6$ for which the experimental value for $\Delta_{r} H$ is $-(148.0 \pm$ $3.0) \mathrm{kJ} \mathrm{mol}^{-1}$, in good agreement with the theoretical calculation, allowing a value of about $-(106.1 \pm 3.8) \mathrm{kJ} \mathrm{mol}^{-1}\left[=-(148.0 \pm 3.0)+(41.9 \pm 2.3) \mathrm{kJ} \mathrm{mol}^{-1}\right]$ to be estimated for the enthalpy of reaction $\mathrm{R} 7$, which involves the ring opening of 1,2-benzisoxazole. Reaction R7 was also studied in the liquid phase (aqueous alcohol) and the value of $\Delta_{r} H$ is $-(112 \pm 8) \mathrm{kJ} \mathrm{mol}^{-1}$ [23], not that different from the one we have considered above. This is not too strange if the isomers have similar solvation energies. From the value of $\Delta_{r} H(\mathrm{R} 7)\left[-(106.1 \pm 3.8) \mathrm{kJ} \mathrm{mol}^{-1}\right]$ and the enthalpy of formation of 2-cyanophenol $\left[(32.8 \pm 2.1) \mathrm{kJ} \mathrm{mol}^{-1}\right]$ [22], we estimate a value of $(138.9 \pm 4.3) \mathrm{kJ} \mathrm{mol}^{-1}$ for the enthalpy of formation of 1,2benzisoxazole. Another interesting comparison involves reaction R8:

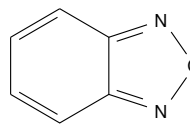

benzofurazan

(X)

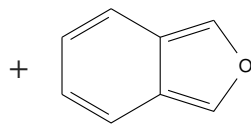

isobenzofuran

(XI)

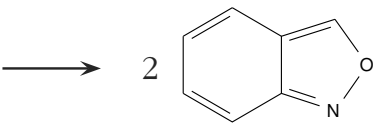

anthranil

(I)

Naively, by neglecting any differential aromaticity effects in the rings and the $\mathrm{N}-\mathrm{O}-\mathrm{N}$ anomeric interaction found only in benzofurazan (X), we are tempted to suggest that this reaction should be thermoneutral. There are three measurements for the enthalpy of formation of gas-phase benzofurazan: (302.3 \pm 2.1$)$ [24], $(300.7 \pm 2.1)[25]$ and 272.7 [26] $\mathrm{kJ} \mathrm{mol}^{-1}$. We believe that the third value can safely be neglected because of "age" and a lack of consensus, and so, we take an average value of $(301 \pm 3) \mathrm{kJ} \mathrm{mol}^{-1}$. No measurements have been reported for isobenzofuran (XI). Computationally, from accurate G3 atomization energies, we got an enthalpy of formation for benzofurazan of $311.1 \mathrm{~kJ} \mathrm{~mol}^{-1}$ while, for isobenzofuran we got $77.3 \mathrm{~kJ} \mathrm{~mol}^{-1}$ from identical level calculations. As referred above, through an acceptable reasoning we could suggest reaction 
Table 9.4. Estimated enthalpies of formation (from atomization reactions).

\begin{tabular}{lrrc}
\hline & G3(MP2) & \multicolumn{1}{c}{ G3 } & \multicolumn{1}{c}{ Exp. } \\
\hline Anthranil & 187.4 & 190.7 & $180.8 \pm 2.1$ \\
Benzoxazole & 30.3 & 33.7 & $44.8 \pm 5.0$ \\
Benzisoxazole & 140.5 & 143.8 & $138.9 \pm 4.3$ \\
2-Cyanophenol & 32.1 & 35.1 & $32.8 \pm 2.1$ \\
Isoxazole & 85.9 & 85.9 & $78.58 \pm 0.54$ \\
& & & $82.0 \pm 0.6$ \\
Oxazole & -11.1 & -11.3 & $-15.5 \pm 0.54$ \\
\hline
\end{tabular}

R8 would likely be approximately thermoneutral; in this case we would obtain an enthalpy of formation of about 189.2 or $194.2 \mathrm{~kJ} \mathrm{~mol}^{-1}$, for anthranil, respectively by using the experimental estimate of the enthalpy of formation of benzofurazan or our G3 estimate of the same parameter. However, accurate computational techniques allows us to go further and calculate the reaction enthalpy as $-7.1 \mathrm{~kJ} \mathrm{~mol}^{-1}$, again from G3 energies and, again, not that different from our conjecture of thermoneutrality. In this case our estimates of the enthalpy of formation of anthranil would be 185.6 or $190.7 \mathrm{~kJ} \mathrm{~mol}^{-1}$, respectively using experimental or computational data for the enthalpy of formation of benzofurazan. In either case we must recognize the quality of our calculations if we consider the close similarity between the last estimates and the experimentally measured value of the enthalpy of formation of anthranyl, $180.8 \pm 2.1 \mathrm{~kJ} \mathrm{~mol}^{-1}$. One may regard both isomers anthranil and 1,2-benzisoxazole as derivatives of 1,2-oxazonine (i.e., 1-oxa-2-aza-2,4,6,8-cyclononatetraene, XII) with an additional transannular $\mathrm{C}-\mathrm{C}$ bond that transforms this monocycle into a bicyclic species with five- and six-membered rings:

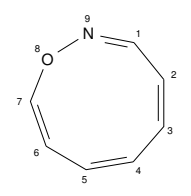

1,2.oxazonine

(XII)

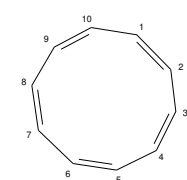

cyclodeca-1,3,5,7,9-pentaene

(XII)

In the absence of any additional information, one would assume that the above procedures would lead to bicyclic systems with very similar enthalpies 
Table 9.5. Nucleus independent chemical shifts (ppm).

\begin{tabular}{lcclcc}
\hline & \multicolumn{2}{c}{ 6-membered-ring } & & \multicolumn{2}{c}{ 5-membered-ring } \\
\cline { 2 - 3 } \cline { 5 - 6 } & NICS(0) & NICS(1.0) & & NICS(0) & NICS(1.0) \\
\hline Anthranil & -6.0 & -8.1 & & -14.8 & -13.0 \\
1,2-benzisoxazole & -10.3 & -11.6 & & -10.8 & -10.1 \\
Benzoxazole & -10.9 & -11.8 & & -9.9 & -9.4 \\
2-cyanophenol & -9.4 & -10.2 & & - & - \\
Oxazole & - & - & & 12.2 & 10.4 \\
Isoxazole & - & - & & 12.6 & 11.0 \\
Phenol & -9.7 & -10.7 & & - & - \\
Benzene & -8.9 & -11.1 & & - & - \\
Benzonitrile & -9.1 & -11.0 & & - & - \\
Naphthalene & -9.3 & -11.5 & & - & - \\
\hline
\end{tabular}

of formation. In fact, as enunciated above, our studies show that the difference is about $42 \mathrm{~kJ} \mathrm{~mol}^{-1}$. This difference is significant, but is far less than the $140 \mathrm{~kJ} \mathrm{~mol}^{-1}$ by which naphthalene is more stable than its aromatic isomer azulene, both of which can be considered as resulting from cyclodeca1,3,5,7,9-pentaene (XIII) through convenient transannular bond formation. This suggests that by thermochemical criteria, if we ascribe aromatic character to 1,2benzisoxazole, then we should ascribe significant aromatic character to anthranil as well. Magnetic properties provide an alternative way of analysing aromaticity [9]. The NICS (nucleus-independent chemical shift) values for the molecules involved in this study have been calculated from the RHF/6-31G* wavefunctions at the most stable B3LYP/6-311G*** geometries the main results being collected in Table 9.5.

The NICS values calculated above the ring and at the center of the ring are in very good agreement with each other and both sets of values indicate that all the species have aromatic character since they have negative values. The benzenic rings of all these systems, with the exception of anthranil, shows NICS values that are consistent with the value found for benzene itself with the same basis set and wavefunctions $[\operatorname{NICS}(0)=-9.7 \mathrm{ppm}]$, but they are slightly more negative. Similar comparisons apply to the NICS calculated at the centre of the five membered rings, which compare with the values found for pyrrole $(-15.1 \mathrm{ppm})$ and furan 
$(-12.3 \mathrm{ppm})$ [9]. The NICS values for anthranil are remarkably different from those of the other compounds studied in this work; anthranil has a larger NICS value for the six-membered ring and a correspondingly lower value for the five-membered ring. This indicates a loss of aromaticity in the six-membered ring and an increase in the aromaticity of the five-membered ring, which seems to be in agreement with our calculations thus suggesting that anthranil is less benzenoid than its isomeric molecules. Benzene and 2-cyanophenol (as well as the monosubstituted phenol and benzonitrile) are not that different in terms of aromaticity. Even benzoxazole and 1,2-benzisoxazole are not that different in terms of their six-membered rings. What about anthranil? Interestingly, in that the sum of the NICS values [(0.0) or (1.0)] for the five- and six membered rings in anthranil is very nearly the same as those for its isomers 1,2-benzisoxazole and benzoxazole, it would appear that the aromaticity of these three species are very nearly the same as well.

\subsubsection{Stability of Chromanone and Coumarin Isomers $[27,28]$}<smiles>O=C1CC2CCCC(O2)c2ccccc21</smiles>

chromanone

(XIV)<smiles>O=C1Cc2ccccc2CO1</smiles>

3-isochromanone

$(\mathbf{X V})$<smiles>O=C1CCc2ccccc2O1</smiles>

dihydrocoumarin

(XVI)<smiles>O=c1ccc2ccccc2o1</smiles>

coumarin

(XVII)<smiles>O=c1ccoc2ccccc12</smiles>

chromanone

Each of the three isomeric chromanones has an optimum geometry consisting of a planar benzenic ring and a heterocyclic ring largely distorted from planarity. Planarity of the last ring is inhibited either by the angular strain within the $s p^{3}$ hybridized carbon atoms as well as the repulsion between contiguous $-\mathrm{CH}_{2}-$ groups. The hydrogen atoms of these fragments are, in fact, observed to adopt almost perfectly mutually staggered conformations for the chromanone 
and dihydrocoumarin isomers. Contrasting with the above behaviour, both coumarin and chromone, systems mainly consisting of $s p^{2}$-hybridized fragments, are found to adopt completely planar structures at their most stable molecular geometries. Indeed, such planar conformation favours the occurrence of stabilizing extended electronic delocalization between all those fragments, which, when involving cyclic structures, evidences the peculiar stabilizing effect we generally call aromaticity.

In order to estimate the enthalpies of formation of the systems from the calculated energies, we used the following set of homodesmic reactions involving auxiliary systems whose thermochemical properties are well established experimentally [21,29-32]:

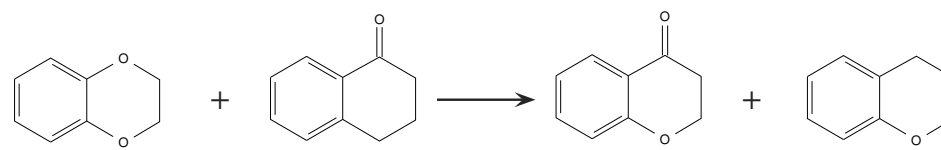

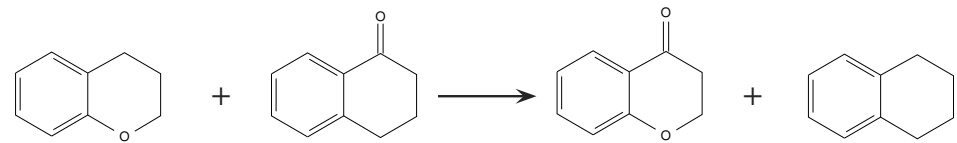<smiles>O=C1C(=O)C2C1CC1c3ccccc3C2c2ccccc21</smiles>
$+$<smiles></smiles>

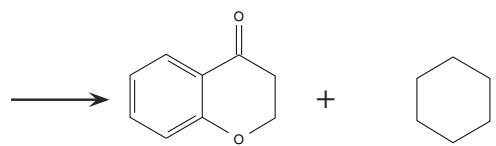

(R9c)<smiles>c1ccc2c(c1)CCCO2</smiles><smiles>O=C1CCCCC1C1CCCCC1</smiles><smiles></smiles><smiles>c1ccc2c(c1)OCCO2</smiles><smiles>[C+]1CCCC1</smiles><smiles>c1ccc2c(c1)CCC1CCC2C1</smiles><smiles>Cc1ccc2c(c1)CCC(=O)O2</smiles><smiles>c1ccc2c(c1)CCCC2</smiles><smiles>c1ccc2c(c1)CCCO2</smiles><smiles>C1CCCC1</smiles><smiles>C1=CCc2ccccc2CC1</smiles><smiles>C1CCCC1</smiles><smiles>O=C1CCc2ccccc2O1</smiles><smiles>c1ccc2c(c1)CCCC2</smiles> 


$$
\begin{aligned}
& \infty+\infty \rightarrow \infty 2+\varnothing \text { mow } \\
& \infty \cdot \sigma r \rightarrow \infty \lambda \cdot \bigcirc \text { am } \\
& \infty \cdot \infty \rightarrow \infty \alpha+\infty \text { mat }
\end{aligned}
$$

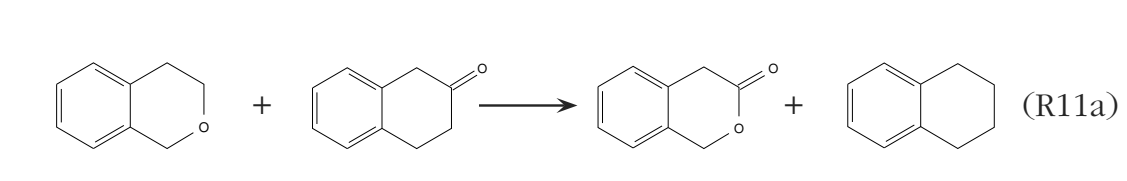

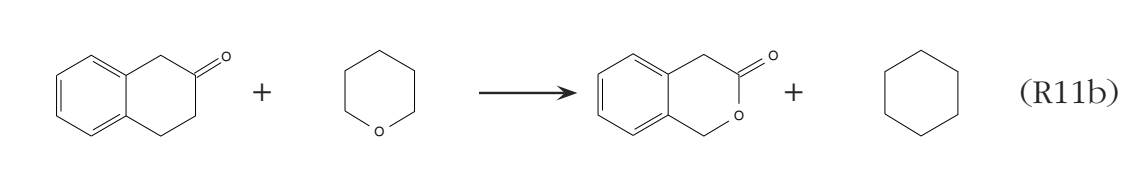

$$
\begin{aligned}
& \infty \cdot b \rightarrow \infty \text { r. } \\
& \infty \cdot \infty \rightarrow \infty d \cdot D_{\operatorname{and}}
\end{aligned}
$$

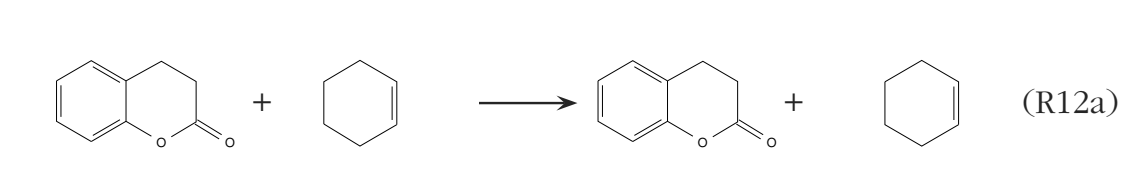

$$
\begin{aligned}
& \infty 2 \cdot 00 \rightarrow \infty \alpha \cdot \cos \alpha
\end{aligned}
$$




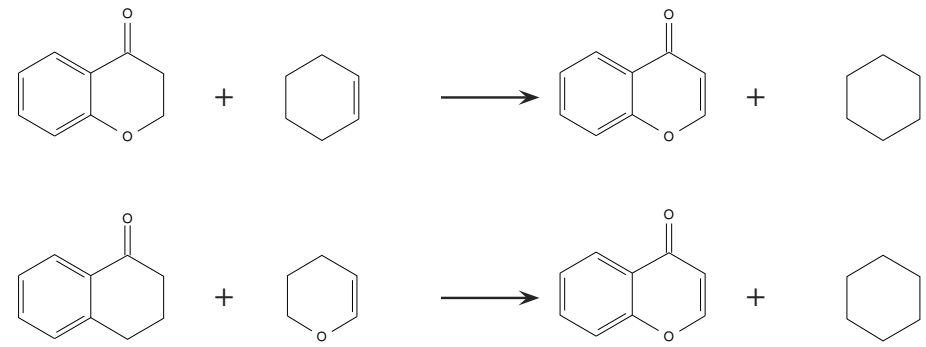

The resulting estimated enthalpies of formation are collected in Table 9.6. Considering first the most saturated set of molecules (chromanone, 3-isochromanone and dihydrocoumarin) we observe a good agreement between our computational estimates and the experimental data, with almost no significant difference between the DFT and the most accurate correlated MC-UT and MC-QCISD results, this being, certainly, an indication of the adequacy of the chosen homodesmotic reactions. Differences between the two sets of calculations become apparent when we consider the estimates of the enthalpies of formation obtained from atomization reactions. Even though we get acceptable results from the MC-UT and MC-QCISD energies, with deviations not exceeding $12.5 \mathrm{~kJ} \mathrm{~mol}^{-1}$, the estimates obtained from the more modest B3LYP energies become clearly unacceptable, since the associated errors can exceed $50 \mathrm{~kJ} \mathrm{~mol}^{-1}$ for the B3LYP/CCPVTZ results and are even worst for the B3LYP/6-311G** ones. The experimentally observed stability ordering, however, is well described by all our calculations, which correctly predict dihydrocoumarin to be the most stable isomer, followed by 3 -isochromanone (about $12 \mathrm{~kJ} \mathrm{~mol}^{-1}$ less stable) and by chromanone (about $44 \mathrm{~kJ} \mathrm{~mol}^{-1}$ more unstable).

Both chromone and coumarin had been experimentally studied previously $[29,33,34]$, but the obtained enthalpies of formation differ considerably from the present measurements. Indeed, the earlier obtained enthalpies of formation of $-176.8 \pm 1.8 \mathrm{~kJ} \mathrm{~mol}^{-1}$ for coumarin and of $-148.5 \pm 2.9 \mathrm{~kJ} \mathrm{~mol}^{-1}$ for chromone are in disagreement with our own measurements by as much as $13.4 \mathrm{~kJ} \mathrm{~mol}^{-1}$ (coumarin) and $22.4 \mathrm{~kJ} \mathrm{~mol}^{-1}$ (chromone), both being predicted as being excessively stable as compared with the present work. 
Table 9.6. Calculated and Experimental Formation Enthalpies at 298.15 K.

\begin{tabular}{|c|c|c|c|c|c|c|c|}
\hline \multirow{3}{*}{ Compound } & \multirow{3}{*}{$\mathrm{R}$} & \multicolumn{6}{|c|}{$-\Delta_{f} H^{\circ}(\mathrm{g}) / \mathrm{kcal} \mathrm{mol}^{-1}$} \\
\hline & & \multicolumn{2}{|c|}{ DFT/B3LYP } & \multirow[t]{2}{*}{ MC-UT } & \multirow[t]{2}{*}{ MC-QCISD } & \multirow[t]{2}{*}{ G3(MP2) } & \multirow[t]{2}{*}{ Exp. } \\
\hline & & $6.311 \mathrm{G}^{* *}$ & cc-pVTZ & & & & \\
\hline \multirow[t]{5}{*}{ Chromanone } & $9 a$ & 202.9 & 202.3 & 198.8 & 199.2 & - & $204.5 \pm 2.4$ \\
\hline & $9 b$ & 202.4 & 202.2 & 201.3 & 201.6 & - & \\
\hline & $9 \mathrm{c}$ & 213.4 & 212.5 & 206.2 & 206.7 & - & \\
\hline & $9 \mathrm{~d}$ & 204.4 & 201.5 & 196.0 & 196.5 & - & \\
\hline & $A t$ & 110.1 & 152.9 & 192.0 & 192.1 & - & \\
\hline \multirow[t]{6}{*}{ Dihydrocoumarin } & $10 \mathrm{a}$ & 239.4 & 238.6 & 233.8 & 234.7 & - & $247.9 \pm 2.3$ \\
\hline & $10 \mathrm{~b}$ & 239.0 & 238.5 & 236.3 & 237.1 & - & \\
\hline & $10 \mathrm{c}$ & 250.0 & 248.8 & 241.2 & 242.2 & - & \\
\hline & $10 \mathrm{~d}$ & 245.7 & 245.0 & 241.9 & 242.5 & - & \\
\hline & $10 \mathrm{e}$ & 251.4 & 249.5 & 247.2 & 246.9 & - & \\
\hline & At & 151.4 & 196.5 & 237.9 & 238.1 & - & \\
\hline \multirow[t]{5}{*}{ 3-Isochromanone } & $11 \mathrm{a}$ & 226.6 & 226.3 & 221.7 & 223.1 & - & $236.4 \pm 2.3$ \\
\hline & $11 b$ & 234.5 & 234.5 & 228.9 & 230.4 & - & \\
\hline & $11 \mathrm{c}$ & 233.4 & 232.8 & 227.3 & 228.5 & - & \\
\hline & $11 d$ & 235.9 & 235.2 & 234.9 & 235.1 & - & \\
\hline & $A t$ & 135.9 & 182.2 & 225.6 & 226.2 & - & \\
\hline \multirow[t]{3}{*}{ Coumarin } & $12 \mathrm{a}$ & 181.8 & 185.8 & 159.7 & 161.5 & 164.2 & $163.4 \pm 3.3$ \\
\hline & $12 \mathrm{~b}$ & 171.5 & 172.1 & 159.5 & 160.8 & 162.3 & $(176.8 \pm 1.8)$ \\
\hline & $A t$ & 80.5 & 129.2 & 140.8 & 143.6 & 173.8 & \\
\hline \multirow[t]{3}{*}{ Chromone } & $13 \mathrm{a}$ & 140.3 & 144.5 & 123.6 & 124.4 & 127.5 & $126.1 \pm 2.5$ \\
\hline & $13 \mathrm{~b}$ & 133.5 & 133.4 & 119.8 & 121.3 & 124.2 & $(148.5 \pm 2.9)$ \\
\hline & At & 42.0 & 88.7 & 103.3 & 104.9 & 134.0 & \\
\hline
\end{tabular}

As can be seen from the results in Table 9.6, our calculations describe very accurately our own experimental data; indeed, with the exception of the results obtained from reaction (13b) and from MC-UT/3 and MC-QCISD/3 calculations, the most accurate composite methods [MC-UT/3, MC-QCISD/3, and G3(MP2)] provide estimates of the enthaply of formation of these compounds with deviations from the experimental data which do not exceed $4 \mathrm{~kJ} \mathrm{~mol}^{-1}$ (i.e., we achieve the standard of "chemical accuracy"). In addition, for the most accurate G3(MP2) calculations, even the results obtained from the atomization processes are in good agreement with what we found experimentally, with deviations not larger than $10.5 \mathrm{~kJ} \mathrm{~mol}^{-1}$, a remarkably accurate result for non-isodesmic reactions. Additional corroboration of our suggested values is that we find a $38.3 \pm 4.1 \mathrm{~kJ} \mathrm{~mol}^{-1}$ difference between the enthalpies of formation of coumarin 
and chromone, as opposed to the earlier $28.3 \pm 3.4 \mathrm{~kJ} \mathrm{~mol}^{-1}$ value, but in agreement with the $c a$. $40 \mathrm{~kJ} \mathrm{~mol}^{-1}$ difference found by our various calculational approaches.

Thus, our very accurate computational estimates correctly describe our experimental data and, on the other hand, crudely diverge clearly from the earlier experimental data of Sabbah and Watik, with deviations of $16 \mathrm{~kJ} \mathrm{~mol}^{-1}$ (coumarin) and $27.2 \mathrm{~kJ} \mathrm{~mol}^{-1}$ (chromone). Consequently, we feel confident to propose our new experimental data as the most reliable ultimate thermochemical data for coumarin and chromone.

Attempting to rationalize the stability order within each set of compounds, we recognize that those isomers which are more stabilized involve the $\mathrm{O}=\mathrm{C}-\mathrm{O}$ fragment (lactone) and we can anticipate that their behaviour is likely to be understood from the interactions involving electron delocalization of the loneelectronic pairs of the oxygen atoms. Quantitatively, such interactions can be probed through an analysis of the wave functions in the framework of Natural Bond Orbital (NBO) theory [10-13], according to which the electronic population should be distributed over a set of localized one-centre ("lone-pair") and two-centre ("bond") orbitals. This localized description closely mimics a classical Lewis-type picture of the electronic system, while delocalization effects are evidenced by small occupancies of the set of anti-bonding orbitals. The stabilizing effect of such delocalization interactions can be quantitatively obtained as second-order perturbative estimates of the corresponding bonding-antibonding interactions. By doing so, we are thus able to identify the leading donoracceptor interactions which are responsible for the differences in the stabilities of the chromanone isomers as being those involving the $\pi$ lone-electronic pair of the ring oxygen and the anti-bonding $\pi_{\mathrm{C}=\mathrm{O}}^{*}$, which contributes with a stabilization energy of about $36 \mathrm{kcal} \mathrm{mol}^{-1}$ and $43 \mathrm{kcal} \mathrm{mol}^{-1}$, respectively for dihydrocoumarin and for 3-isochromanone, and the $\pi$ lone-electronic pair of the carbonyl oxygen and the anti-bonding $\sigma_{\mathrm{C}-\mathrm{O}}^{*}$ involving the carbon atom of the same group and the other oxygen atom, contributing with $36 \mathrm{kcal} \mathrm{mol}^{-1}$ and $34 \mathrm{kcal} \mathrm{mol}^{-1}$, respectively for dihydrocoumarin and for 3-isochromanone. Note that neither 
of the above interactions is allowed to occur in chromanone. The other important interaction justifying differences in stability involve electronic delocalization from the $\pi$ lone-electronic pair of the ring oxygen to the closer anti-bonding $\pi_{\mathrm{C}=\mathrm{C}}^{*}$ of the benzenic ring. This interaction, which is absent in 3-isochromanone, contributes a stabilization of about $22 \mathrm{kcal} \mathrm{mol}^{-1}$ and $28 \mathrm{kcal} \mathrm{mol}^{-1}$, respectively for dihydrocoumarin and chromanone. Considering now the isomeric pair coumarin/chromone, we find that both experiment and our computational results predict coumarin to be more stable than chromone (by about $37.3 \pm 4.1 \mathrm{~kJ} \mathrm{~mol}^{-1}$ ), a feature which can again be ascribed to the peculiar structure of the former isomer involving the much more stable $\mathrm{O}-\mathrm{C}=\mathrm{O}$ (lactone) fragment. We also recall that this ester fragment has considerable stabilization energy, identified as resonance energy and comparable to that of $\mathrm{N}-\mathrm{C}=\mathrm{O}$, i.e., the highly stabilized isoelectronic amide group [35,36]. Similarly to what we found above, coumarin, the unsaturated analog of the most stable dihydrocoumarin, is also the most stable isomer. Considering only the homologous pairs of both classes of compounds, we can observe that dihydrocoumarin is $43.4 \pm 3.3 \mathrm{~kJ} \mathrm{~mol}^{-1}$ more stable than chromanone while coumarin is only $37.3 \pm 4.1 \mathrm{~kJ} \mathrm{~mol}^{-1}$ more stable than chromone, thus evidencing an attenuation of the stabilizing capacity of the $\mathrm{O}-\mathrm{C}=\mathrm{O}$ fragment by somewhat more than $6 \mathrm{~kJ} \mathrm{~mol}^{-1}$. As we stressed before, the enhanced stability afforded by that fragment results from the possibility of involvement of the lone-electronic pairs of both oxygen atoms in conjugative or hyperconjugative mutual interactions, which are especially important for these isomers, since the $\mathrm{O}-\mathrm{C}=\mathrm{O}$ fragment can directly interact with the contiguous aromatic ring, thus enhancing the extended electronic delocalization. Thus, fragmentation of this group results in the observed stability differences, but the destabilizing effect is less pronounced for the pair coumarin/chromone, since, in the latter system, the intercalation of a $\mathrm{C}=\mathrm{C}$ double bond between both oxygen atoms in the pyrone ring still tends to allow the mutual interactions involving the respective $\pi$-lone electronic pairs to occur, thus avoiding the destabilization becoming so severe for these systems. These interactions involving both $\pi$-lone electronic pairs through the $\mathrm{C}=\mathrm{C}$ double bond should presumably be evid- 
Table 9.7. Nucleus independent chemical shifts (ppm).

\begin{tabular}{lcclcc}
\hline & \multicolumn{2}{c}{ Benzene ring } & & \multicolumn{2}{c}{ Pyrone ring } \\
\cline { 2 - 3 } \cline { 5 - 6 } & NICS(0.0) & NICS(1.0) & & NICS(0.0) & NICS(1.0) \\
\hline Coumarin & -9.40 & -10.69 & & -0.42 & -3.24 \\
Chromone & -10.27 & -11.30 & & 0.41 & -3.12 \\
Benzene & -9.7 & -11.5 & & - & - \\
2-Pyrone & - & - & & -1.3 & -3.8 \\
4-Pyrone & - & - & & -0.2 & -3.4 \\
Naphthalene & -9.3 & -11.5 & & -9.3 & -11.5 \\
1,2-dihydroNapht. & -7.8 & -10.3 & & +2.6 & -0.7 \\
\hline
\end{tabular}

enced by some aromatic character in the pyrone ring of the coumarin, while no aromatic character should be evidenced by the homologous ring of dihydrocoumarin. In fact, nucleus independent chemical shifts (NICS) calculated from the corresponding B3LYP/6-311G*** wave functions of both systems indicate that the NICS values at the center of the pyrone ring of chromanone and $1.0 \AA$ above it are, respectively, $+2.49 \mathrm{ppm}$ and $-0.16 \mathrm{ppm}$, while the corresponding values for dihydrocoumarin are $+0.45 \mathrm{ppm}$ and $-0.73 \mathrm{ppm}$, respectively. These findings thus indicate essentially no aromatic character for both systems, even though the out of plane NICS value at the pyrone ring of dihydrocoumarin is somewhat more negative (the ring is consequently somewhat more aromatic), which is certainly a consequence of the electronic interactions involving the lone electronic pairs of both oxygen atoms integrating the fragment $\mathrm{O}-\mathrm{C}=\mathrm{O}$. In contrast, the NICS values for chromone (and also for coumarin) reported in Table 9.7 indicate a moderate aromatic character of the pyrone ring of both systems, as is likewise shown for the monocyclic 2- and 4-pyrones as well. How aromatic are these pyrones? Enthalpy of formation data for these monocyclic pyrones, or any substituted derivative thereof, appear to be absent [37]: while the isomerization enthalpy interrelating 4-methoxy-6-methyl-2-pyrone and 2-methoxy-6-methyl-4pyrone has been measured,[38] the presence of the exocyclic methoxy groups confounds comparison, as we have insufficient thermochemical knowledge of enol ethers and dialkoxyalkenes, as well as with pyrones of any type. 
Complementing the above analysis of aromaticity based on magnetic property values we can also study the aromaticity of the studied systems on the basis of energetic criteria. We might think that both species (coumarin and chromone) should be rather aromatic, since they are $\pi$-isoelectronic or isoconjugate to the aromatic hydrocarbon, naphthalene, much as furan is related to benzene. The hydrogenation enthalpies of dihydrocoumarin and chromanone (dihydrochromone) can easily be obtained from their formation enthalpies and from the known formation enthalpy of molecular hydrogen; we thus find the enthalpies of hydrogenation to be $-78.4 \pm 3.5$ and $-84.5 \pm 4.4 \mathrm{~kJ} \mathrm{~mol}^{-1}$, respectively, for dihydrocoumarin and for chromanone. By contrast, the likewise derived hydrogenation enthalpy of the aromatic naphthalene to 1,2-dihydronaphthalene (using the enthalpy of formation of the former from Ref. 39 and the latter from Ref. 40 ) is the far smaller $-24.3 \pm 1.6 \mathrm{~kJ} \mathrm{~mol}^{-1}$. The coumarin and chromone values are comparable to that of the 1,2-dihydronaphthalene with its nonaromatic ring to tetralin (1,2,3,4-tetrahydronaphthalene; data from Ref. 21), numerically $100.3 \pm 2.2 \mathrm{~kJ} \mathrm{~mol}^{-1}$. Equivalently, the value for coumarin resembles that of the nonaromatic dihydronaphthalene more than that of the aromatic naphthalene, where we remind the reader that we are referring to the second "non-benzenoid" ring in the dihydrospecies. Alternatively, with precedent to the energetics of 1-ring species and the "experimental realized Dewar-Breslow model" of Ref. 41 we find, for the "aromatic" naphthalene and ring-opened trans-stilbene, the enthalpy of formation difference of $75.5 \mathrm{~kJ} \mathrm{~mol}^{-1}$ while, for the "non-aromatic" 1,2-dihydronaphthalene, the difference is $23.6 \mathrm{~kJ} \mathrm{~mol}^{-1}$. The difference for coumarin and phenyl benzoate is but $20.8 \mathrm{~kJ} \mathrm{~mol}^{-1}$. This again documents that coumarin lacks aromaticity other than found in its benzene ring. The above analysis cannot be applied to chromone. However, in that chromone contains the same groups as coumarin, the fact that coumarin is rather much more stable than chromone suggests that chromone likewise lacks aromatic character beyond that of its benzene ring as well. 


\section{References}

[1] A. Curtiss, K. Raghavachari, P. C. Redfern, V. Rassolov, J. A. Pople, J. Chem. Phys. 109, 7764 (1998); L. A. Curtiss, K. Raghavachari, The Encyclopedia of Computational Chemistry, P. v. R. Schleyer (editor-in-chief), John Wiley \& Sons Ltd, Athens, USA, 2, 1104 (1998); L. A. Curtiss, P. C. Redfern, K. Raghavachari, V. Rassolov, J. A. Pople, J. Chem. Phys. 110, 4703 (1999); A. G. Baboul, L. A. Curtiss, P. C. Redfern, K. Raghavachari, J. Chem. Phys. 110, 7650 (1999).

[2] P. L. Fast, J. Corchado, M. L. Sanchez, D. G. Truhlar, J. Phys. Chem. A 103, 3139 (1999); J. M. Rodgers, P. L. Fast, D. G. Truhlar, J. Chem. Phys. 112, 3141 (2000); B. J. Lynch, D. G. Truhlar, J. Phys. Chem. A 107, 3898 (2003); B. J. Lynch, D. G. Truhlar, J. Phys. Chem. A 107, 8996 (2003); B. J. Lynch, D. G. Truhlar, J. Phys. Chem. A 109, 1643 (2005).

[3] Y. Zhao, D. G. Truhlar, J. Phys. Chem. A. 108, 6908 (2004); Y. Zhao, B. J. Lynch, D.G. Truhlar, J.Phys. Chem. A. 108, 4786 (2004); Y. Zhao, B. J. Lynch, D. G. Truhlar, Phys. Chem. Chem. Phys. 7, 43 (2005).

[4] M. R. Nyden, G. A. Petersson, J. Chem. Phys. 75, 1843 (1981); G. A. Petersson, M. A. Al-Laham, J. Chem. Phys. 94, 6081 (1991); G. A. Petersson, T. G. Tensfeldt, J. A. Montgomery Jr., J. Chem. Phys. 94, 6091 (1991); J. A. Montgomery Jr., J. W. Ochterski, G. A. Petersson, J. Chem. Phys. 101, 5900 (1994); J. W. Ochterski, G. A. Petersson, J. A. Montgomery Jr., J. Chem. Phys. 104, 2598 (1996); J. A. Montgomery Jr., M. J. Frisch, J. W. Ochterski, G. A. Petersson, J. Chem. Phys. 112, 6532 (2000); J. A. Montgomery Jr, M. J. Frisch, J. W. Ochterski, G. A. Petersson, J. Chem. Phys. 110, 2822 (1999).

[5] T.H. Dunning Jr., J. Chem. Phys. 90, 1007 (1989); R. A. Kendall, T. H. Dunning, Jr., R. J. Harrison, J. Chem. Phys. 96, 6796 (1992); D.E. Woon, T.H. Dunning Jr., J. Chem. Phys 98, 1358 (1993); D.E. Woon, T.H. Dunning Jr., J. Chem. Phys. 100, 2975 (1994); D. E. Woon, T. H. Dunning, Jr., J. Chem. Phys. 103, 4572 (1995); A. K. Wilson, T. van Mourik, T. H. Dunning, Jr., J. Mol. Struct. THEOCHEM 388, 339 (1996); A.K. Wilson, D.E. Woon, K. A. Peterson, T. H. Dunning Jr., J. Chem. Phys. 110, 7667 (1999). 
[6] D. G. Truhlar, Chem. Phys. Lett. 294, 45 (1998); W. Klopper, J. Chem. Phys. 115, 761 (2001), F. Jensen, Theor. Chem. Accounts, 113, 267 (2005); A. Karton, J. M. L. Martin, Theor. Chem. Accounts, 115, 330 (2006).

[7] A. J. C. Varandas, J. Chem. Phys. 113, 8880 (2000); A. J. C. Varandas, J. Chem. Phys. 126, 244105 (2007); A. J. C. Varandas, Chem. Phys.Lett., 443, 398 (2007); A. J. C. Varandas, J. Chem. Phys 127, 114316 (2007); A. J. C. Varandas, Theor. Chem. Accounts 119, 511 (2008); A. J. C. Varandas, J. Chem. Phys 129, 234103 (2008); A. J. C. Varandas, Chem. Phys.Lett., 471, 315 (2009); A. J. C. Varandas, J. Chem. Phys 131, 124128 (2009).

[8] T. Helgaker, W. Klopper, H. Koch, and J. Noga, J. Chem. Phys. 106, 9639 (1997); A. Halkier, T. Helgaker, P. Jørgensen, W. Klopper, H. Koch, J. Olson, A. K. Wilson, Chem. Phys. Lett. 286, 243 (1998); A. Halkier, T. Helgaker, W. Klopper, P. Jørgensen, A. G. Császár, Chem. Phys. Lett. 310, 385 (1999).

[9] P. v. R. Schleyer, C. Maerker, A. Dransfeld, H. Jiao, N. J. R. v. E Hommes, J. Am. Chem. Soc. 118, 6317 (1996).

[10] A. E. Reed, L. A. Curtiss, F. Weinhold, Chem. Rev. 88, 899 (1988).

[11] J. P. Foster, F. Weinhold, J. Am. Chem. Soc. 102, 7211 (1980).

[12] A. E. Reed, F. Weinhold, J. Chem. Phys. 78, 4066 (1983).

[13] E. D. Glendening, J. K. Badenhoop, A. E. Reed, J. E. Carpenter, J. A. Bohmann, C. M. Morales, F. Weinhold, NBO 5.0, Theoretical Chemistry Institute, University of Wisconsin, Madison, 2001.

[14] D. Becke, J. Chem. Phys. 98, 5648 (1993).

[15] T. Lee, W. T. Yang, R. G. Parr, Phys. Rev. B 37, 785 (1998).

[16] M. M. Francl, W. J. Pietro, W. J. Hehre, J. S. Binkley, M. S. Gordon, D. J. DeFrees, J. A. Pople, J. Chem. Phys. 80, 3654 (1982).

[17] P. C. Hariharan, J. A. Pople, Chem. Phys. Lett. 16, 217 (1972).

[18] P. C. Hariharan, J. A. Pople, Theor. Chim. Acta 28, 213 (1973); M. J. Frisch, J. A. Pople, J. S. Binkley, J. Chem. Phys. 80, 3265 (1984).

[19] P. A. Scott, L. Radom, J. Chem. Phys. 100, 16502 (1996).

[20] M. A. R. Matos, M. S. Miranda, V. M. F. Morais, J. F. Liebman, Eur. J. Org. Chem. 15, 3340 (2004). 
[21] J. B. Pedley, Thermochemical Data and Structures of Organic Compounds, TRC Data Series, College Station, Texas, vol. 1, 1994.

[22] The standard molar enthalpy of 2-cyanophenol is from: M. A. R. Matos, M. S. Miranda, V. M. F. Morais, Struct. Chem. 15, 99 (2004).

[23] M. L. Casey, D. S. Kemp, K. G. Paul, D. D. Cox, J. Org. Chem. 38, 2294 (1973).

[24] M. L. Leitão, G. Pilcher, W. E. Acree, Jr., A. I. Zvaigzne, S. A. Tucker, M. D. M. C. Ribeiro Da Silva, J. Chem. Thermodyn. 22, 923 (1990).

[25] M. T. Arshadi, J. Chem. Thermodyn. 12, 903 (1980).

[26] C. R. Brent, PhD Thesis, Tulane University, New Orleans, 1963.

[27] M. A. R. Matos, C. C. S. Sousa, V. M. F. Morais, J. Chem. Thermodyn., 41 , 308 (2009).

[28] M. A. R. Matos, C. C. S. Sousa, M. S. Miranda, V. M. F. Morais, J. F. Liebman, J. Phys. Chem. B 113, 11216 (2009).

[29] S. Verevkin, Thermochim. Acta 310, 229 (1998).

[30] M. A. R. Matos, C. C. S. Sousa, V. M. F. Morais, J. Chem. Thermodyn. 40, 1552 (2008).

[31] M. A. R. Matos, C. C. S. Sousa, V. M. F. Morais, J. Phys. Chem. A 112, 7961 (2008).

[32] M. A. R. Matos, C. C. S. Sousa, V. M. F. Morais, J. Chem. Thermodyn. 41, 308 (2009).

[33] R. Sabbah, L. E. Watik, Bull. Soc. Chim. Fr. 4, 626 (1988).

[34] L. E. Watik, R. Sabbah, Bull. Soc. Chim. Fr. 128344 (1991).

[35] J. F. Liebman, A. Greenberg, Biophys. Chem. 1, 222 (1974).

[36] A. Greenberg, Y. Chiu, J. L. Johnson, J. F. Liebman, Struct. Chem. 2, 117 (1991).

[37] L. Lorenz, H. Sternitzke, Elektrochem. Z. Angew. Phys. Chem. 40, 501 (1934). While these authors assert pyrone, as found in its 2,6-diphenyl derivative, "resembles the benzene ring", no data is in fact given therein to further discuss this point.

[38] P. Beak, Tetrahedron 20, 631 (1964); P. Beak, D. S. Mueller, J. Lee, J. Am. 
Chem. Soc. 963867 (1974).

[39] M. V. Roux, M. Temprado, J. S. Chickos, Y. Nagano, J. Phys Chem. Ref. Data 37, 1855 (2008).

[40] R. D. Chirico, W. V. Steele, J. Chem. Thermodyn. 40, 806 (2008).

[41] R. S. Hosmane, J. F. Liebman, Tetrahedron Lett. 32, 3949 (1991). 